\title{
Professores de língua materna e estrangeira na sociedade tecnológica: perspectivas atuais e tendências de mercado
}

\author{
Maria Helena da Nóbrega \\ Universidade de São Paulo (USP), São Paulo, São Paulo, Brasil \\ mhn135@usp.br
}

DOI: http://dx.doi.org/10.21165/el.v46i2.1742

\begin{abstract}
Resumo
Ao divulgar o conteúdo apresentado em minicurso no $64^{\circ}$ Seminário do GEL, este texto discorre sobre as possibilidades de atuação para profissionais de língua materna e estrangeira. EJA, Libras, tecnologia educacional, português para falantes de outras línguas no Brasil e no exterior, o trabalho nas editoras e no mercado audiovisual estão entre as escolhas possíveis, nem sempre de forma excludente. Essa diversificação sugere que o profissional deve estabelecer estratégias para alcançar as metas definidas para a própria carreira. Para finalizar, os participantes avaliam vagas reais de emprego, considerando os benefícios oferecidos em cada caso.
\end{abstract}

Palavras-chave: professor; revisor; língua portuguesa; tecnologia.

Teachers of native and foreign language in technological society: current perspectives and market trends

\begin{abstract}
To spread the content presented in the mini course of the $64^{\text {th }}$ GEL [Group of Linguistic Studies] Seminar, this text discusses the possibilities of performance for professionals of native and foreign language. Adult education, Brazilian sign language, educational technology, Portuguese for speakers of other languages in Brazil and abroad, the occupation in publishing houses and audiovisual media are among possible choices, not always in an exclusive way. This diversification suggests that the professional should set up strategies to achieve the goals for his own career. To conclude, the participants assess real jobs opportunities, considering the benefits offered in each particular case.
\end{abstract}

Keywords: teacher; proofreader; Portuguese language; technology.

\section{Considerações iniciais}

Neste texto apresento as questões abordadas no minicurso do $64^{\circ}$ Seminário do Grupo de Estudos Linguísticos do Estado de São Paulo (GEL), realizado na UNESP Faculdade de Ciências e Letras, campus de Assis, em julho de 2016. O objetivo é demonstrar diversas formas de atuação profissional aos estudantes de línguas, literaturas e culturas. Tanto os iniciantes como os prestes a finalizar a graduação de Letras podem se beneficiar com o conteúdo. No primeiro caso, as reflexões buscam conscientizar sobre a importância de definir áreas de atuação, a partir das aptidões e interesses pessoais, bem como estabelecer, desde o início do curso, um planejamento de carreira que permita alcançar as metas estabelecidas. Para os formandos, o aproveitamento advém de demonstrar o mercado de trabalho e as formas de profissionalização sustentável, sobretudo se alicerçadas em formação continuada e permanente. 
Inicialmente, demonstro o destaque atribuído à competência verbal na sociedade contemporânea. Mais do que em qualquer outra época, ler e escrever são condições mínimas para interagir nas práticas sociais da atualidade. Essa obrigatoriedade de destreza verbal, que cada vez mais se amplia para o letramento digital, atribui valor aos que lidam com esses temas e detêm o domínio dessas ferramentas: profissionais de Letras e de tecnologia da informação, de uma maneira geral.

Além disso, a ampliação ocorrida nos processos comunicativos - blogs, Facebook, Twitter, Instagram, Youtube - altera irremediavelmente os cenários pedagógicos, pois os profissionais precisam estar preparados para atuar em novos formatos de ensino/aprendizagem, que ocorrem em contextos presenciais ou a distância, formais ou informais. Há evidências de que, nas aulas de língua materna e estrangeira, as práticas são muito variadas e as inovações dependem apenas da criatividade de professores e alunos.

Como resultado, o profissional de Letras deve conscientizar-se de que é fundamental valorizar a área de sua atuação, reconhecendo a ampla demanda pelo conhecimento linguístico e cultural no cenário globalizado.

$\mathrm{Na}$ sequência, este texto analisa o contexto da atualidade e situa a língua portuguesa no mercado linguístico da atualidade. A seguir, desmistificando a restrição de mercado atribuída aos profissionais de Letras, exemplifica-se com atuações que podem ser desempenhadas por esses profissionais no cenário nacional e internacional. Finalmente, possibilidades além da docência são demonstradas, sobretudo no ambiente corporativo e nas editoras.

\section{Contexto da atualidade}

Mudanças radicais ocorreram em todo o mundo nas últimas décadas. Computadores, telefones celulares, tablets e internet, para citar apenas alguns novos meios, integram o dia a dia das pessoas e tudo indica que vieram para ficar. Essas novas formas de comunicação transformaram rapidamente a maneira de agir, o estilo de vida, a atitude das pessoas.

Vivemos num mundo cada vez mais móvel, tanto física quanto virtualmente. Fluxos de pessoas, conhecimentos, ideias e objetos estão todos em aceleração, levando a novas interações entre as pessoas e a novas formas de aprendizagem online e offline. A língua se torna um importante veículo, que pode sustentar, dirigir, impedir e canalizar esses fluxos. (BARTON; LEE, 2015, p. 91).

Essas modificações entraram também na sala de aula. As relações de poder, por exemplo, sofreram abalo e reconstruíram as hierarquias existentes. $\mathrm{O}$ acesso imediato e ininterrupto às informações da internet permite que o aluno confira continuamente $o$ conteúdo da aula, podendo contribuir para a construção do conhecimento. Disso decorre que o professor não tem mais o papel centralizador de distribuidor do conhecimento, que, aliás, pode ser acessado facilmente na rede digital.

No setor de divulgação, um exemplo na alteração das relações de poder pode ser notado nos blogueiros que fazem sucesso com produções digitais e, depois disso, passam a ser procurados pelas editoras para imprimir e divulgar os seus textos. Esses novos escritores saem da internet para as editoras, do digital para o impresso. O reconhecimento 
desses autores pôde ser comprovado na $24^{\text {a }}$ Bienal Internacional do Livro, em São Paulo, em 2016, que contou com a presença de webcelebridades e youtubers que possuem de dois a cinco milhões de inscritos e seguidores. O sucesso de jovens como Maju Trindade, Christian Figueiredo, Kéfera Buchmann e Lucas Rangel, por exemplo, era impensável antes da internet, que os lança no mercado rapidamente, com números estrondosos tanto na quantidade de seguidores como na conta bancária.

As virtualidades tecnológicas promovem o deslocamento da página para a tela, (BARTON; LEE, 2015), com inegável ênfase da imagem. Tantas modificações permitem prever o surgimento de novas profissões: condutor de drone, técnico em telemedicina, conselheiro de aposentadoria, mecânico de robô pessoal, consultor de simplificação, especialista em desintoxicação digital etc. (OLIVETTE, 2016).

A questão é: quais as influências dessas modificações para o profissional de Letras? Conectando a palavra à imagem estática ou em movimento, as redes sociais se tornaram mecanismos de comunicação poderosos e colocaram o texto em posição de destaque na cena social. Como preparar o profissional de Letras para atuar nesse cenário? A educação, como as demais áreas, precisa se adaptar a essas mudanças, para poder criar profissionais que saibam responder às necessidades do mercado. Trata-se de preparar para o futuro, e não para o passado.

A avalanche dessas produções digitais vai sendo aos poucos examinada pelas pesquisas linguísticas (BARTON; LEE, 2015), que as acolhem no ensino formal, renovando as práticas pedagógicas e o material didático, como segue.

\section{A docência}

De maneira geral, a sociedade identifica a atuação do professor no ensino fundamental e médio, nas escolas públicas e privadas. Fora isso, o público costuma relacionar essas opções restritas a baixo salário. Embora essa realidade seja verdadeira, essas alternativas não são as únicas possibilidades para o professor.

A EJA - Educação de Jovens e Adultos - acontece em escolas estaduais paulistas desde 2000 e vem transformando a vida de pessoas que não puderam concluir seus estudos na idade adequada. O ensino fundamental, a partir de 15 anos, e o ensino médio, a partir de 18 anos, são projetos de inclusão para esses alunos. Por serem relativamente novas, as propostas da EJA ainda precisam ser incorporadas pelos cursos de formação de professores.

Diversos cursos de licenciatura não demonstram interesse em fazer com que os futuros docentes reflitam sobre as questões inerentes à EJA, e a mudança dos princípios que regem a metodologia de ensino com inclusão de tecnologias é ainda menos debatida e estudada na formação de docentes. (COSTA, 2012, p. 28).

Outra atuação pouco conhecida é o ensino de Libras - Língua Brasileira de Sinais. Trata-se da educação para surdos, garantida em lei desde 2002. Novamente, o caráter inclusivo salta aos olhos. A internet disponibiliza aulas e materiais didáticos, bem como o dicionário de Libras. No entanto, ainda faltam políticas educacionais vigorosas nessa especificidade, com vistas a neutralizar a intolerância ainda vigente. "As línguas de sinais, cada vez mais, têm conquistado espaço no contexto educacional, porém, ainda há 
resquícios de preconceito proveniente do estigma que sofreram os surdos e sua língua de sinais no período oralista" (ALMEIDA, 2012, p. 21).

Essas duas possibilidades de atuação docente merecem ser divulgadas, pois podem ser fonte de realização pessoal por permitirem atuar como agente de transformação da sociedade.

O segmento da educação a distância $(\mathrm{EaD})$ não pode ser ignorado na esfera da docência, como demonstra o acentuado crescimento desse setor.

Sua evolução [da educação a distância] se mostra grandiosa: de 20.658 ingressos em 2002 para 430.259 em 2008 (crescimento superior a 20 vezes). Em 2005 houve um salto de $407,9 \%$ nos ingressos, denotando possivelmente o ano da virada. As matrículas cresceram por volta de 18 vezes no período. Os concluintes cresceram por volta de 41 vezes, saindo de $1.712 \mathrm{em}$ 2002, para $70.068 \mathrm{em} \mathrm{2008.} \mathrm{Embora} \mathrm{acuse} \mathrm{um} \mathrm{recuo} \mathrm{em} 2007$ (crescimento de apenas 15,5\%), em 2008 o crescimento foi de 235\%. (DEMO, 2010, p. 23).

Esse tema suscita várias questões: que tipo de formação o professor deve ter para atuar adequadamente na EAD? Além do conhecimento técnico, deve-se considerar que ele vai gravar o vídeo da aula - como se comunicar com alunos que não estão na sua presença? Há exemplos bem-sucedidos na internet, e isso sugere que essa habilidade comunicativa deve ser praticada nos cursos de formação.

O fato é que a tecnologia educacional não parece ser moda passageira, e os computadores, instalados nas universidades brasileiras desde o final dos anos 1980, passaram a fazer parte das políticas educacionais, que vêm investindo gradativamente nesse setor.

Nunca, na história da tecnologia, houve tanto apoio governamental para a socialização de uma tecnologia. Telecentros continuam sendo criados por todo o país, e a informatização das escolas tem constituído esforço conjunto dos governos municipais, estaduais e federal.

No final de 2008, o Ministério da Educação realizou licitação para compra de 150 mil computadores portáteis para atender a 300 escolas brasileiras, implementando a política de um computador por aluno. Em 2012, anunciou o investimento de cerca de R $\$ 150$ milhões para a compra de 600 mil tablets para uso dos professores do ensino médio de escolas públicas federais, estaduais e municipais. As Secretarias de Educação, em todo o país, também se movimentam para levar a tecnologia digital às escolas. A do Estado de Minas Gerais, por exemplo, está equipando as escolas com lousas digitais. (PAIVA, 2015, p. 32-33).

Além disso, surge a problemática da adequação do conteúdo para EaD. Para um bom aproveitamento da tecnologia, é preciso investir em novas configurações educacionais, e não apenas repetir o que funcionou no ensino presencial, pois " [...] a construção da aprendizagem está cada vez mais na participação em redes e na utilização de letramentos multissemióticos ou de multiletramentos" (MOITA LOPES, 2006, p. 92). As ferramentas disponíveis incluem e-mails, chats, fóruns, com os quais os alunos geralmente demonstram ampla familiaridade. É fundamental criar interatividade e situações que envolvam aplicação do conhecimento, troca de experiências e autoavaliação. 
Paralela à docência há, ainda, a possibilidade de atuar na criação de material didático, área vasta e com farto mercado, sobretudo se considerarmos a utilização das tecnologias digitais, e não apenas o material impresso. Os games educativos também aguardam incrementação. Como exemplo do que tem sido criado nessa área, consulte-se o BIOE - Banco Internacional de Objetos Educacionais: $<$ http://objetoseducacionais2.mec.gov.br/>.

As animações do BIOE, abrangendo diferentes áreas e vários níveis de ensino, podem encorajar a criação de material para o ensino de língua portuguesa. Há alguns jogos nessa área, mas a demanda é grande e carece de profissionais em no mínimo duas frentes específicas: i) tradução de jogos educativos criados em outras línguas e ii) criação de jogos educativos em língua portuguesa e sobre a língua portuguesa, para falantes nativos e estrangeiros. Por exemplo: um jogo sobre o Acordo Ortográfico poderia facilitar a memorização das novas regras e seria útil aos usuários.

No entanto, antes mesmo de inserir a tecnologia no contexto educacional, é indispensável que os métodos de ensino sejam renovados. Há propostas com metodologias já testadas e resultados positivos, como a aprendizagem baseada em problemas. Nessa metodologia de ensino, os alunos trabalham em grupo,

[...] identificando problemas na realidade científica e cotidiana; discutindo um problema particular; utilizando seus próprios conhecimentos e experiências, com o auxílio de professores e outros meios, na busca de respostas para o problema abordado; levantando uma série de hipóteses que podem explicar e resolver o problema; procurando investigar as hipóteses apontadas e apontar possíveis respostas e/ou soluções; no final do processo, preparando um relatório acadêmico contendo reflexões teóricas e análises sobre o problema estudado e socializando os resultados do projeto desenvolvido com o coletivo da classe. (ARAÚJO; ARANTES, 2009, p. 107).

Além do ensino de língua portuguesa para falantes nativos, deve-se considerar a expansão do ensino de português para falantes de outras línguas (PFOL), que pode ocorrer tanto no Brasil como no exterior.

Em solo brasileiro, vale a pena lembrar a população indígena, que o Censo Demográfico de 2010 computou em aproximadamente um milhão (HAAG, 2010). Espalhados em cerca de 260 povos, essas etnias contabilizam entre 150 a 180 línguas diferentes, muitas delas ameaçadas de extinção devido à baixa taxa de transmissão para as novas gerações. Muitos desses indígenas têm a língua materna de seu grupo étnico e aprendem a língua portuguesa em contexto formal, o que justifica a importância da formação de professores para as escolas indígenas.

Ainda no contexto brasileiro, cresce o número de escolas de idiomas que contratam professores de PFOL, devido ao aumento na demanda desses cursos, decorrente da multiplicação no número de estrangeiros que vêm trabalhar no Brasil e moram aqui em caráter temporário ou definitivo. Para esse público, há as escolas bilíngues e as internacionais. As primeiras seguem o currículo brasileiro, e as internacionais não precisam ter esse compromisso. Todas as disciplinas são ministradas na língua do país que elas representam - inglês, francês, espanhol, alemão -, e PFOL faz parte do currículo, com as especificidades que lhe são próprias.

Além dos executivos estrangeiros que atuam em empresas brasileiras, os intercambistas frequentam os campi das universidades brasileiras. Como faltam 
professores com a formação específica em ensino de PFOL, muitas escolas solicitam que os professores de inglês deem aula de português, na crença ingênua de que ser falante nativo em língua portuguesa é condição suficiente para ensinar PFOL, o que é uma inverdade. Sem a formação adequada em ensino de línguas estrangeiras, o professor desconhece propostas da linguística aplicada, esbarra em dificuldades e fica à deriva nas metodologias existentes (LEFFA, 1988).

No exterior, além das lições de português em embaixadas ou centros e associações de estudos brasileiros, há cursos de língua portuguesa e cultura brasileira e/ou portuguesa em diversas universidades do mundo, por exemplo: em Macau (China), Hanói (Vietnã), Praga (República Tcheca), Estocolmo (Suécia) e em muitas universidades dos EUA, como Georgetown (Washington), Harvard (Boston), Yale (New Haven), Columbia (New York), Stanford (Palo Alto) e muitas outras.

As vagas dessas instituições são divulgadas em editais definidos pela universidade estrangeira, CAPES e Ministério das Relações Exteriores. O processo de seleção de 2015, por exemplo, selecionou profissionais para a Universidade de Heidelberg (Alemanha), Universidade de Pequim (China), Pontifícia Universidade Javeriana (Colômbia), Universidade Zagreb (Croácia), Universidade de Aarhus (Dinamarca), Universidade de Valladolid (Espanha), Universidade de Pittsburgh (EUA), King's College/London (Inglaterra) e outras.

Quem se interessa pelo mercado de trabalho no exterior deve se preparar desde a graduação, pois a seleção se distancia cada vez mais do nepotismo dos anos 1960, quando os profissionais dessas vagas eram pessoas sem formação na área de linguística aplicada ou de ensino, normalmente desempenhando funções nas embaixadas. Hoje os critérios são rígidos, e como pré-requisitos para as candidaturas exige-se experiência comprovada no ensino de português para estrangeiros, além de proficiência na língua do país em que se vai trabalhar ou, em alguns casos, em inglês ou francês. Nesse mercado, há professores que fazem carreira internacional, morando por dois ou quatro anos em um país e depois migrando para outro.

Outra esfera pouco considerada na docência situa-se no ensino superior, em que a atuação acontece na graduação, pós-graduação, nos cursos de extensão e nas atividades de pesquisa. Legalmente, o professor deve ter no mínimo curso de especialização de $360 \mathrm{~h}$. No entanto, essa condição mínima não será suficiente para seguir carreira ou prestar concurso nas universidades públicas, que exigem mestrado e doutorado. Quem almeja ser professor universitário, portanto, deve levar em conta que os estudos, a pesquisa, enfim, fazem parte do percurso e precisam acontecer continuamente. Se o professor não se atualizar, ele vai fornecer noções desatualizadas, principalmente devido à substituição rápida dos conceitos da atualidade.

Um problema que tem sido apontado no ensino superior envolve questões didáticas. Há professores com comprovado conhecimento técnico, tanto porque cursaram a pós-graduação nesses temas, como porque têm experiência na área em questão, no entanto, nunca tiveram práticas de didática para pensar e repensar os métodos que utilizam nas aulas. Pesquisas avaliam a maneira como a didática é tratada em diferentes períodos históricos, até o momento presente, como na obra citada a seguir. 
Dessa maneira, a valorização do ensino e da formação pedagógica do professor universitário deveria demandar, em primeiro lugar, a alteração do modo como as questões pedagógicas são entendidas e tratadas na universidade, para assim superar a crença de que para ser bom professor basta conhecer profundamente e conseguir transmitir com clareza determinado conteúdo [...] (GONÇALVES; ROCHAEL, 2015, p. 13).

Muitas mudanças, portanto, estão acontecendo na forma de conceber e fazer a construção do conhecimento no ensino superior. Como Barton e Lee (2015, p. 209) exemplificam, "o Twitter é muitas vezes adotado por acadêmicos como suporte para discussões eletrônicas em tempo real em seminários e conferências [...] e palestras em universidades".

Grande parte dessas modificações é impulsionada pelas novas tecnologias, que promovem encontros de ensino e aprendizagem em contextos formais e informais, como salas de bate-papo online, conferências de áudio e vídeo, fóruns de discussão etc. De anatomia a línguas, de matemática a astronomia, cada vez mais os conteúdos estão disponibilizados na rede global de computadores. Por isso, há autores que defendem a atualização no papel do professor, não para transmitir conhecimento, mas para incentivar o aluno a pensar e aprender a aprender.

Apenas expor conteúdos, mesmo que de modo não instrucionista, vai se tornando tarefa virtual, agregada em vídeos, DVDs, ambientes eletrônicos, plataformas virtuais, portais etc., onde os alunos podem encontrar os conteúdos expostos, com a vantagem de que podem ser continuamente atualizados. (DEMO, 2010, p. 14).

Para a aprendizagem de línguas, há trocas acontecendo por Skype, além de os professores utilizarem cada vez mais o conteúdo de sites e blogs, para que os alunos compartilhem suas produções e estabeleçam interação com os colegas. As palestras do TED (Technology, Entertainment, Design), por exemplo, fornecem conferências que podem ser usadas para praticar a compreensão da língua alvo. Os temas são apresentados em vídeos rápidos, de no máximo 18 minutos, e englobam ciência, cultura e questões gerais da atualidade. Divulgados abertamente na internet, os vídeos ganharam popularidade e podem ser assistidos gratuitamente: $<$ https://www.ted.com/>.

Para além da docência, profissionais de Letras também encontram amplo campo laboral no ambiente corporativo, nas editoras e na indústria audiovisual.

\section{Para além da docência}

Grandes empresas se conscientizam da importância de ter funcionários com bom domínio linguístico, pois são eles que irão representá-las em textos escritos em e-mails, e oralmente, em eventos de divulgação externa. Dessa forma, os processos de seleção buscam escolher candidatos com competência oral e escrita, muitas vezes não apenas na língua materna, mas também em línguas valorizadas no competitivo mercado linguístico da atualidade. O profissional de Letras, portanto, pode atuar como consultor em ambientes de multilinguismo.

A elaboração de material didático é uma possibilidade a ser explorada, tanto em textos impressos como em materiais digitais. As coleções didáticas, a leitura crítica de 
obras literárias, a avaliação de material para publicação, a busca de imagens ilustrativas, tudo isso exige profissionais altamente capacitados e procurados por editoras bemconceituadas.

O fato é que a divulgação das obras hoje acontece não apenas no contexto formal das editoras, mas também em blogs. A autopublicação é uma realidade na era tecnológica, e multiplicam-se os autores de e-books, pela facilidade de divulgar no ambiente digital. Há plataformas que oferecem divulgação no mundo todo e percentuais de direito autoral maiores do que as casas de publicação de obras impressas, ainda muito restritas para escritores desconhecidos do grande público.

Quer seja texto impresso ou digital, os profissionais de preparação de original e revisão de texto são necessários, ou seja: são fundamentais peritos com excelente domínio do idioma. A seleção de textos - o que publicar, afinal? - requer profissionais conectados com os interesses do mercado e, ao mesmo tempo, capazes de fazer análises prospectivas sobre o que poderá causar impacto de venda. Tais prospecções são complexas e por vezes surpreendem até profissionais experientes, como foi o caso dos livros para colorir, que empolgaram os adultos em 2015. De conteúdo técnico a obras de ficção, todos os temas são possíveis e atualmente as obras religiosas são o segmento de maior estabilidade em vendas.

O interessado em atuar com publicações deve primeiramente identificar qual temática lhe entusiasma mais e buscar especializar-se na área. Além de ler muito sobre o tema escolhido, convém fazer cursos com conteúdos técnicos específicos.

No tocante à indústria audiovisual, há registros de ausência de profissionais de legendagem, roteirista, redator de sinopses de filmes, crítico literário. Esses trabalhos não se destinam apenas aos profissionais de Letras, mas também não os exclui. É provável que a complementação curricular seja indispensável, por exemplo, fazendo cursos sobre legendagem, para conhecer programas de computador indispensáveis nesse ofício. As oficinas literárias também podem ser úteis, pois é fato que o mercado cinematográfico e televisivo está à caça de roteiristas criativos. Construir uma formação multidisciplinar, enfim, faz com que o profissional amplie suas chances de mercado.

Poliglotas são naturalmente bem-vindos na sociedade multilíngue e multicultural. Tradutores, portanto, podem atuar como freelancers, oferecendo seus trabalhos para editoras ou para particulares. Novamente a sugestão é especializar-se, sobretudo em temas de maior interesse pessoal. Isso facilita o trânsito em determinadas áreas, por exemplo: tradução de obras de culinárias, ou de manuais técnicos, ou de obras literárias etc. Se a proficiência da língua estrangeira for bem avançada, além da tradução (da língua estrangeira para o português) é possível trabalhar também com versão (do português para a língua estrangeira). Finalmente, a tradução juramentada - de documentos oficiais - é uma possibilidade laboral, mas o tradutor deve ser aprovado em concurso estadual.

No domínio das línguas estrangeiras, há diversas oportunidades para atuar como intérprete, quer em eventos oficiais ou em situações informais, ajudando estrangeiros em viagens ou compras. Contextos profissionais multilíngues e multiculturais, como é o caso da ONU (Organização das Nações Unidas), que reúne quase 200 nações, seriam impraticáveis se não houvesse interpretação simultânea ou consecutiva dos discursos. A importância do intérprete vem se firmando nas sociedades globalizadas contemporâneas. 
Até aqui, fica evidente a multiplicidade de caminhos disponíveis para os egressos do curso de Letras. Essas possibilidades devem ser sempre visualizadas a partir da tecnologia, que cria processos disruptivos em todos os setores e altera as regras vigentes até então. O Airbnb e o Uber são exemplos das alterações promovidas no setor hoteleiro e na rede de transporte mundial, respectivamente. Essa revolução implica alterações nas relações comerciais, motivadas por mudanças irreversíveis no campo informacional. No setor educacional, as instituições devem dar suporte para os professores acompanharem as inovações.

Toda e qualquer instituição que resolva adotar a EaD [Educação a Distância] em seu sistema de ensino deve, por igual, providenciar um suporte técnico que assessore os professores, quando necessário, que administre todo o processo, e que, sintonizada com os avanços tecnológicos, possa indicar novas perspectivas e soluções para o cenário educacional mediado pela tecnologia, um aspecto essencial quando lidamos com ambientes em constante mutação. (QUEVEDO, 2015, p. 164).

Sem definir a própria rota, é provável que o aluno desperdice o potencial oferecido por uma boa preparação. Fundamental, portanto, que ele seja orientado a delimitar suas escolhas desde a graduação.

\section{Gerenciamento de carreira}

Neste quesito, o minicurso incitou os participantes à autoanálise. Dos temas trabalhados no curso de Letras, com quais você se identifica? Você se vê trabalhando com literatura? Língua materna ou estrangeira? No Brasil ou no exterior? Docência para crianças, adolescentes ou adultos? Tradução? Interpretação? Cada um deve responder para si, buscando identificar interesses.

Feito isso, cabe uma análise realista das aptidões. É muito produtivo que a autoanálise consiga identificar pontos fortes e aspectos a melhorar. Se a intenção é trabalhar na preparação de original, é fundamental fortalecer o conhecimento da língua portuguesa aplicada à produção textual: morfologia, sintaxe, estilística, pragmática, semântica etc. Todos os estudos oferecidos no curso de Letras são indispensáveis e, por isso, o aluno deve dedicar-se a eles desde a graduação. Se o propósito é atuar como intérprete, a proficiência da língua alvo precisa ter nível avançado para ler, escrever, ouvir e falar. O resultado dessa autoavaliação depende dos conhecimentos prévios e, portanto, cada um deve buscar complementar as lacunas da própria formação com estudos individuais, tendo em conta que o processo é contínuo e permanente.

O principal erro no planejamento de carreira consiste em transferir a responsabilidade da escolha e das atitudes para outra pessoa. Assim, disciplina e persistência são aspectos fundamentais para o alcance dos objetivos, cuja busca depende da própria pessoa.

A sugestão é que o futuro profissional avalie o mercado e procure brechas nas quais sua contribuição seja mais relevante. A partir disso, ele deve enviar o currículo a escolas, ou editoras, ou empresas pelas quais tenha interesse. É importante frisar que todas as informações do currículo devem ser verdadeiras. Se o candidato afirma ter nível avançado de inglês, por exemplo, ele deve estar preparado para entrevista nessa língua, pessoalmente ou por telefone. 
Uma novidade é gravar um videocurrículo e colocá-lo na internet - essa é uma opção ainda pouco explorada no Brasil e, por isso mesmo, de destaque no mercado brasileiro. Novamente, a criatividade na forma destaca o conteúdo apresentado. Vale a pena conferir exemplos no YouTube.

No final do curso, os participantes realizaram análise de anúncios de emprego, reais e atuais, no Brasil e no exterior. Em primeiro lugar, eles avaliaram as pretensões pessoais e as relacionaram à cultura do empregador. Benefícios e vantagens também devem ser considerados, tendo em conta as particularidades de cada caso. Horário de trabalho e localização são fatores importantes, sobretudo quando se considera o tempo gasto no deslocamento até o emprego. Finalmente, vale considerar, como Demo (2010, p. 8), que "oportunidades não são dadas, semeadas a esmo, ou impostas. São construídas, dentro das circunstâncias dadas".

\section{Considerações finais}

Partindo das reflexões sobre o cenário pedagógico do século XXI, o minicurso demonstrou áreas de atuação para profissionais de Letras, destacando a perspectiva tecnológica. Nas aulas de língua materna ou estrangeira, os espaços formativos combinam ambientes e utilizam recursos online para diferentes estilos de aprendizagem. E-aulas, $e$ books, jogos e aplicativos educacionais, livros didáticos com propostas interativas são exemplos de novos formatos para contextos formais ou informais de ensino/aprendizagem.

Demonstrando as possibilidades atuais e as tendências de mercado, o minicurso incentivou os participantes a estabelecer estratégias a partir de seus interesses e suas competências individuais. O principal é desenvolver a habilidade de aprender de forma permanente, para ganhar sustentabilidade em um mundo de rapidez e instabilidade intensas. Trata-se de valorizar não apenas o texto impresso, mas estar atento às novas formas de comunicação. Além disso, o trabalho em equipe deve ser enaltecido, pois o conhecimento constrói-se coletivamente.

O minicurso ressaltou que o planejamento de carreira bem definido permite obter profissionalização sustentável e realização pessoal nas atividades desempenhadas por professores, avaliadores, elaboradores de material didático, tradutores, revisores, redatores e consultores linguísticos em geral.

\section{REFERÊNCIAS}

ALMEIDA, J. J. F. de. Libras na formação de professores: percepções dos alunos e da professora. 2012. 151 f. Dissertação (Mestrado em Educação) - Centro de Educação, Comunicação e Artes, Universidade Estadual de Londrina, Londrina. Disponível em: $<$ http://www.uel.br/pos/mestredu/images/stories/downloads/dissertacoes/2012/2012__ALMEIDA_Josiane_Junia_Facundo.pdf>. Acesso em: 14 ago. 2016.

ARAÚJO, U. F.; ARANTES, V. A. Comunidade, conhecimento e resolução de problemas: o projeto acadêmico da USP Leste. In: ARAÚJO, U. F.; SASTRE, G. (Org.). Aprendizagem baseada em problemas no ensino superior. São Paulo: Summus, 2009. p. 101-121. 
BARTON, D.; LEE, C. Linguagem online: textos e práticas digitais. Tradução de Milton Camargo Mota. São Paulo: Parábola, 2015.

COSTA, A. B. de C. e. Letramento digital na educação básica de jovens e adultos. In: ALMEIDA, M. G. de; FREITAS, M. do C. D. (Org.). A escola no século XXI - v. 2 Docentes e discentes na sociedade da informação. Rio de Janeiro: Brasport, 2012. p. 2143.

DEMO, P. Outra universidade. 2010. Disponível em: $<$ http://www.prograd.ufscar.br/PedroDemo_OutraUniversidade.pdf $>$. Acesso em: 18 ago. 2016.

GONÇALVES, M. G.; ROCHAEL, M. C. N. A importância da didática para a formação docente do ensino superior. In: Revista Científica da FEPI - Fundação de Ensino e Pesquisa de Itajubá. Itajubá. v. 7, 2015. p. 1-31. Disponível em: $<$ http://www.fepi.br/revista/index.php/revista/article/view/253/142>. Acesso em: 18 ago. 2016.

HAAG, C. Diversidade brasileira. In: Revista FAPESP. São Paulo: Fapesp, jul. 2010. p. 86-89.

LEFFA, V. Metodologia do ensino de línguas. In: BOHN, H. I.; VANDRESEN, P. Tópicos em linguística aplicada: o ensino de línguas estrangeiras. Florianópolis: Ed. da UFSC, $1988 . \quad$ p. 211-236. Disponível em: $<$ http://www.leffa.pro.br/textos/trabalhos/Metodologia_ensino_linguas.pdf $>$. Acesso em: 7 set. 2016.

MOITA LOPES, L. P. da. Linguística aplicada e vida contemporânea: problematização dos construtos que têm orientado a pesquisa. In: aplicada indisciplinar. São Paulo: Parábola, 2006. p. 85-107. (Org.). Por uma linguística

OLIVETTE, C. Estudo identifica profissões do futuro. In: O Estado de S. Paulo. São Paulo, 14 ago. 2016. Caderno de Empregos. p. 2.

PAIVA, V. L. M. de O. e. O uso da tecnologia no ensino de línguas estrangeiras. In: JESUS, D. M. de; MACIEL, R. F. (Org.). Olhares sobre tecnologias digitais: linguagens, ensino, formação e prática docente. Campinas: Pontes, 2015. p. 21-34.

QUEVEDO, A. A inclusão de tecnologias digitais de informação e comunicação na prática pedagógica de professores do ensino superior. In: JESUS, D. M. de; MACIEL, R. F. (Org.). Olhares sobre tecnologias digitais: linguagens, ensino, formação e prática docente. Campinas: Pontes, 2015. p. 161-178.

Recebido em: 03/10/2016

Aprovado em: 29/11/2016 